University of Wollongong

Research Online

Faculty of Engineering and Information

Faculty of Engineering and Information

Sciences - Papers: Part A

Sciences

$1-1-2013$

A study on the suitability of cable models to simulate switching transients in a $132 \mathrm{kV}$ underground cable

Muhamad Zalani Daud

University of Malaysia

P Ciufo

University of Wollongong, ciufo@uow.edu.au

S Perera

University of Wollongong, sarath@uow.edu.au

Follow this and additional works at: https://ro.uow.edu.au/eispapers

Part of the Engineering Commons, and the Science and Technology Studies Commons

Research Online is the open access institutional repository for the University of Wollongong. For further information contact the UOW Library: research-pubs@uow.edu.au 


\title{
A study on the suitability of cable models to simulate switching transients in a $132 \mathrm{kV}$ underground cable
}

\begin{abstract}
Switching transients resulting from the energisation of high voltage cable systems may have a significant effect on both the cables being switched as well as the power system components in the vicinity. The impacts of these transients on such cables are measured based on the stress arising as a result of the voltage and current peaks and the frequency of oscillatory transients. These quantities are typically obtained from a simulation by using a suitable cable model, normally with the capability to predict the transient behaviour in the range up to several $10 \mathrm{kHz}$. To obtain a cable model that enables the accurate determination of the switching transient behaviour of a cable system in service, comparison of simulated data with actual measured data is a vital process before the cable model is selected and then used for further transient analysis. Statistical studies are then carried out to simulate the stress experienced by the underground cable under study. In this paper, the authors have carried out studies on the suitability of various cable models available in PSCAD/EMTDC investigate the ability of the two available FrequencyDependent (FD) cable models in predicting the peak, frequency and oscillatory nature of current energisation transients resulting from the switching of an unloaded $132 \mathrm{kV}$ underground cable. Using the most accurate cable model evaluated from the first stage of the study, a statistical analysis of overvoltage distribution to analyse the over-voltage stress at the sending and receiving ends of the cable is also presented. This study employed two different techniques based on probabilistic and deterministic approaches to measure the distribution of over-voltages at the sending and receiving ends of the cable.
\end{abstract}

\section{Keywords}

models, cable, suitability, study, simulate, switching, underground, kv, transients, 132

\author{
Disciplines \\ Engineering | Science and Technology Studies
}

\section{Publication Details}

M. Daud, P. Ciufo \& S. Perera, "A study on the suitability of cable models to simulate switching transients in a $132 \mathrm{kV}$ underground cable," Australian Journal of Electrical and Electronics Engineering, vol. 10, (1) pp. 45-54, 2013. 


\title{
A study on the suitability of cable models to simulate switching transients in a $132 \mathrm{kV}$ underground cable ${ }^{*}$
}

\author{
MZ Daud \\ University Malaysia Terengganu, Kuala Terengganu, Malaysia \\ P Ciufo ${ }^{+}$and S Perera \\ University of Wollongong, NSW, Australia
}

\begin{abstract}
Switching transients resulting from the energisation of high voltage cable systems may have a significant effect on both the cables being switched as well as the power system components in the vicinity. The impacts of these transients on such cables are measured based on the stress arising as a result of the voltage and current peaks and the frequency of oscillatory transients. These quantities are typically obtained from a simulation by using a suitable cable model, normally with the capability to predict the transient behaviour in the range up to several $10 \mathrm{kHz}$. To obtain a cable model that enables the accurate determination of the switching transient behaviour of a cable system in service, comparison of simulated data with actual measured data is a vital process before the cable model is selected and then used for further transient analysis. Statistical studies are then carried out to simulate the stress experienced by the underground cable under study. In this paper, the authors have carried out studies on the suitability of various cable models available in PSCAD/EMTDC to investigate the ability of the two available frequency-dependent cable models in predicting the peak, frequency and oscillatory nature of current energisation transients resulting from the switching of an unloaded $132 \mathrm{kV}$ underground cable. Using the most accurate cable model evaluated from the first stage of the study, a statistical analysis of over-voltage distribution to analyse the over-voltage stress at the sending and receiving ends of the cable is also presented. This study employed two different techniques based on probabilistic and deterministic approaches to measure the distribution of over-voltages at the sending and receiving ends of the cable.
\end{abstract}

KEYWORDS: Overvoltage; switching transient; underground cable; statistical method.

REFERENCE: Daud, M. Z., Ciufo, P. \& Perera, S. 2013, "A study on the suitability of cable models to simulate switching transients in a $132 \mathrm{kV}$ underground cable", Australian Journal of Electrical \& Electronics Engineering, Vol. 10, No. 1, pp. 45-54, http:/ /dx.doi.org/10.7158/ E11-037.2013.10.1.

\section{INTRODUCTION}

Switching operations in distribution and transmission neworks can cause significant over-voltages in the System. Studies to determine the switching overvoltage are considered to be of primary importance in electric power system insulation coordination. Their role in insulation coordination has been widely

Paper E11-037 submitted 15/09/11; accepted for publication after review and revision 13/12/11.

+ Corresponding author Dr Philip Ciufo can be contacted at ppc@uow.edu.au. researched (Indulkar \& Kothari, 1996; Lee \& Poon, 1990; Marzinotto et al, 2005; Thomas et al, 1989; Yu et al, 2000). The closing of a circuit breaker (CB) to energise a high voltage cable system introduces oscillatory transients that are characterised by their magnitude, duration and spectral content. Normally, their frequency can increase up to the range of tens of kilohertz and last several milliseconds before settling down to the steady-state condition (IEEE, 1995). The factor that influences the impact of oscillatory transients in underground cable systems is primarily related to the energy stored in the system at the instant of switching (Zhenchong et al, 2006). The 
degree of stress imposed on cable insulation depends on several factors such as the point-on-wave (POW) switching of the sinusoid, the length of the cable system, system and network impedances and many more influences (Zhenchong et al, 2006; Kho et al, 2009; Gole et al, 2009).

Studies related to underground cable switching are normally performed with particular interest in avoiding insulation breakdown, or minimising transient stress on the insulation systems as well as the transmission and distribution equipment. The varying characteristics of transients induce different levels of failure of electrical equipment (IEEE, 1995). In general, characterisation of over-voltage stress may be performed by the following means (IEC, 2006):

- the maximum peak values

- a statistical over-voltage of the peak values

- a statistical over-voltage value generated by particular events with a peak value that has a $2 \%$ probability of being exceeded.

Such statistical overvoltage values are normally obtained by means of commercial transient programs that offer various options of closing time ranging from one-shot deterministic closings to multi-shot statistical or systematic closings (Gole et al, 2009).

To undertake such studies, electricity utilities require suitable cable models that can be used to predict energisation transients of underground high voltage cables. Accurate modelling and simulation of such behaviour provides guidance in the determination of the adequacy of protection schemes. Underground cable modelling, for example, has become a topic of ongoing interest and research over many years. Some of the difficult factors of modelling the underground cables include their distributed nature, frequency dependent parameters and the asymmetrical arrangement of coupled conductors with ground return (Marti et al, 1993).

As a result of decades of development of electromagnetic transient simulators, reasonable accuracy can mostly be achieved for the case of overhead lines. Many time domain distributed parameter travelling wave transmission line models can be reliably used (Marti, 1982; Noda et al, 1996; Semlyen \& Dabuleanu, 1975). Recent developments in modelling includes novel frequency-domain-based methods by Semlyen \& Ramirez (2008) for the calculation of the transient response of transmission lines and underground cables. Many of these developed models have been verified for most cases of transmission lines rather than the underground cable counterparts which, as a result, the applicability and validity of underground cable models currently incorporated in electromagnetic transient simulation platforms remains questionable and requires further development.

A number of ATP/EMTP cable models such as the PI, KC Lee and Semlyen models have been previously modelled and investigated, resulting in an inconsistent prediction of the simulated current transient (Nichols et al, 2007). Assessment of the Bergeron model has also been performed by calculation and experimental measurement for the case of switching of coaxial cables, however, this model used constant parameters that are only valid at certain frequency range (Zhenchong et al, 2006). Other similar studies are available for different configurations of cable systems (Kho et al, 2009; Jung et al, 2009), however in these cases, the validation of the cable model performance was not compared with real-life experimental measurement. In this context, more accurate models such as the universal line model (ULM) (Morched et al, 1999) and the L Marti (Marti, 1988) underground cable model are required instead. The ULM forms the FD-Phase model as a standard model in PSCAD/EMTDC, whereas Marti (1988) is currently not available. However, the FD-Mode model based on Marti (1982) is generally valid for certain cases of transient studies. The main difference between Marti (1988) and Marti (1982) is the way their transformation matrices are formed.

Selection of a suitable model for the cable under investigation is therefore a vital part that needs to be studied carefully before it is further used for studies of the behaviour of oscillatory switching transients on the cable systems being considered. Thus, the aim of the present study is:

1. To explore the suitability of FD-Mode and FDPhase models in PSCAD/EMTDC by comparison with the data obtained from the energisation of an unloaded $132 \mathrm{kV}$ underground cable. A suitable cable model will be selected for further studies.

2. To investigate the stress experienced at the sending and receiving end of the cable under study. The data are to be compared with the values indicated by IEC standard for particular cases of the field results and studies.

In the present investigation, a power system network model has been developed using PSCAD/EMTDC to represent an actual network comprising part of power system network commissioned by Endeavour Energy (EE). The cable system to be investigated is a $132 \mathrm{kV}$ underground cable linking Baulkham Hills transmission substation to Bella Vista zone substation as illustrated in figure 1.



Figure 1: The network represents the location of $132 \mathrm{kV}$ underground cable under study (feeder 212). 
It is of great importance to include detailed modelling of system components in the vicinity, such as the upstream overhead lines as well as the distribution transformers. Such specific modelling of surrounding networks should be at least up to one bus away from the switching location as recommended in Gole et al (2009). In the network under investigation, power is supplied by a $132 \mathrm{kV}$ upstream source through several kilometres overhead transmission feeders. This transmission line is amongst the major components that characterise the travelling surges from the switching of an underground cable. The transmission feeders are modelled using a frequency dependent approach.

The measurement data for the purpose of comparison with simulated results from PSCAD/EMTDC models are obtained from the energisation of feeder 212 in the EE network. This feeder is the $5.6 \mathrm{~km}$ cable system shown in figure 1. The local-end CB is first isolated (for approximately 10 minutes) to de-energise the cable. The loads are also disconnected to reduce their impact on the transient to be observed. After a period of time that allows capacitive elements to fully discharge, the CB is closed to energise the cable and the resulting high frequency current transient data were recorded.

The same procedure is replicated in the simulation $i$ chiding the differences in pole closing times of the $\mathrm{CB}$ at the local end. Both measured and simulated current energisation transients are compared to evaluate the suitability of PSCAD/EMTDC coble models.

The rest of the paper is organised as follows. Section 2 describes the development of the underground cable model. The process of creating both an FDMode and FD-Phase model is presented. Section 3 prosents a comparison of the simulated results with the measured data. Section 4 is a discussion on the statistical analysis of cable stress arising from the transients as a consequence of energisation. The POW switching is considered from both a deterministic and probabilistic approach. Finally, section 5 presents sereral concluding remarks.

\section{UNDERGROUND CABLE MODEL DEVELOPMENT}

In the simulation study, the cable system (feeder 212) is represented by two different frequency-dependent (FD) models:

1. Erequency-dependent (mode) model or FD-Mode

2. frequency-dependent (phase) model or FD-Phase.

\section{An overview of frequency dependent models}

The FD models available in PSCAD/EMTDC are based on travelling wave methods and are derived from a set of telegrapher's equations given by:

$-d V / d x=Z I$

$-d I / d x=Y V$

where $V$ and $I$ are vectors representing the voltages and currents at a distance $x$ along the cable system. $Z$ and $Y$ are the corresponding impedance and admittance matrices respectively. The formulation of impedance and admittance parameters, taking into account the frequency dependence of the cable system, is generally performed by cable constant (CC) routines in EMTDC-type simulators. In multi-conductor systems, where conductors are mutually coupled, a set of coupled equations are obtained as following:

$-d^{2} V / d x^{2}=Z Y V$

$-d^{2} I / d x^{2}=Y Z I$

Equations (3) and (4) are then broken up into modes so that the variables can be solved respectively in the modal domain. In this case, modal transformation matrices may be required and can be obtained from eigenvalue analysis performed by $\mathrm{CC}$ routines (Manitoba HVDC Research Center, 2005). Curve fitting (CF) calculations are also performed using CC for the frequency dependent distributed parameter travelling wave models in PSCAD/EMTDC.

\section{$2.2 \quad$ FD-Mode model}

The FD-Mode model that is incorporated in PSCAD/ EMTDC is based on a formulation from Marti (1982). It assumes a real- and constant-transformation matrix to decouple the phase variables of equations (3) and (4) into mode variables to be solved. The transformation of voltage and current variables into modes (matrix diagonalisation) can be derived by the following:

$V=T_{v} V^{\prime}$

$I=T_{i} I^{\prime}$

$T_{v}^{T}=T_{i}^{-1}$

where $V^{\prime}$ and $I^{\prime}$ are the modal voltages and currents. $T_{7}$ and $T_{i}$ are the corresponding voltage and current transformation matrices, respectively. This model is considered to be reliable for most cases of overhead lines but not for underground cables where parameters exhibit strong frequency dependence. Nevertheless, a reasonably good accuracy can be still achieved for certain cases of underground cable by using the assumption of Marti (1982).

\subsection{FD-Phase model}

The difficulties associated with handling the frequency dependence transformation matrix, as outlined in Marti (1982), are transcended through 
direct formulation in the phase domain introduced by the FD-Phase model (Morched et al, 1999). The matrix elements of the propagation function and the characteristic admittance, which defines the behaviour of waves over the conductors are fitted directly in the phase domain. This model is theoretically the most accurate since it represents the frequency dependence of internal transformation matrices (Manitoba HVDC Research Center, 2005). The details regarding implementation of this model in EMTDC-type programs as a standard model is described in Gustavsen et al (1999).

\section{COMPARISON OF MEASURED AND SIMULATED DATA}

Measurement of the phase-current energisation transients were obtained using an oscilloscope, which sampled the current at $250 \mathrm{kHz}$. The time domain plots are to be compared with simulated data of two cable models outlined in section 2, which has been developed in PSCAD/EMTDC. Further analysis of the corresponding frequency response of cable models considered are also presented in the following sections.

\subsection{Experimental test results}

The measured blue- and white-phase current transients are depicted in figure 2 . The waveforms were recorded for approximately $30 \mathrm{~ms}$ following the energisation of the cable. These signals were then filtered with a third-order Butterworth highpass filter with the cut-off frequency set at 200 $\mathrm{Hz}$ to remove low frequency components before converting to the frequency domain plots as shown in figure 3 . This process was undertaken to avoid low frequency signals from dominating the frequency spectrum.

From figure 2, the transient envelope time for the blue-phase is approximately $13 \mathrm{~ms}$ whereas the white-phase transient envelope is seen to last $10 \mathrm{~ms}$. The blue-phase current magnitude peak is close to $713 \mathrm{~A}$ whereas the white-phase peak is approximately equal to $527 \mathrm{~A}$. The lower peak magnitude for the white-phase current is due to the lower instantaneous voltage magnitude at the switching instant. The waveforms also seem naturally distorted due to strong electromagnetic coupling effects between phases.

Figure 3 shows the frequency response plot for the data in figure 2. It is intended to measure the ability of the model in predicting the dominant peaks in the frequency spectrum. In this case, results from the simulation should be able to predict the component frequency behaviour over the specified calculation range. From the energy spectral density plots of figure 3 , it is evident that the frequency spectra of the blue- and white-phase signals are dominant in the
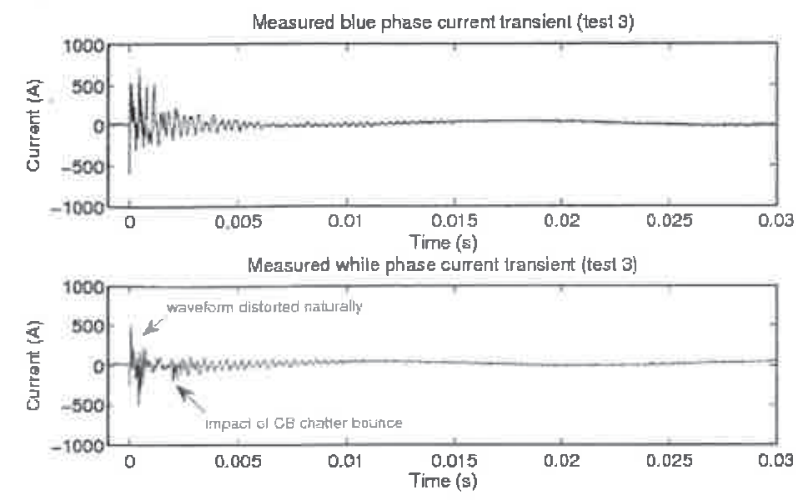

Figure 2: Time domain plot of measured blue-phase and white-phase current energisation transients.
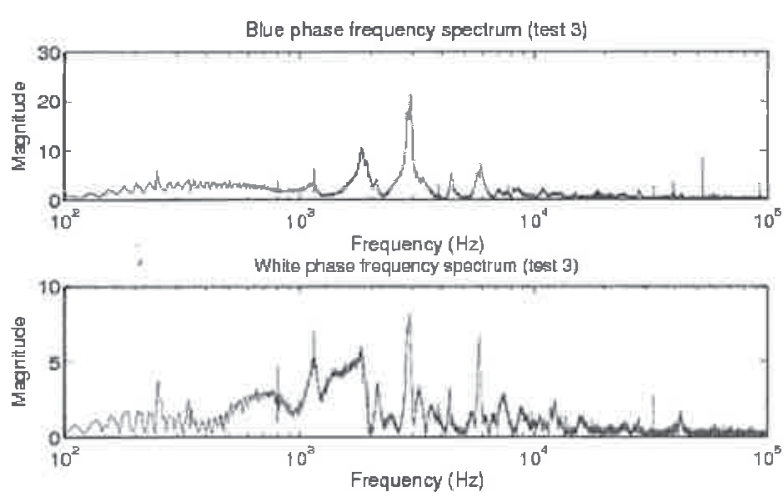

Figure 3: Frequency spectrum of measured blue-phase and white-phase current energisation transients.

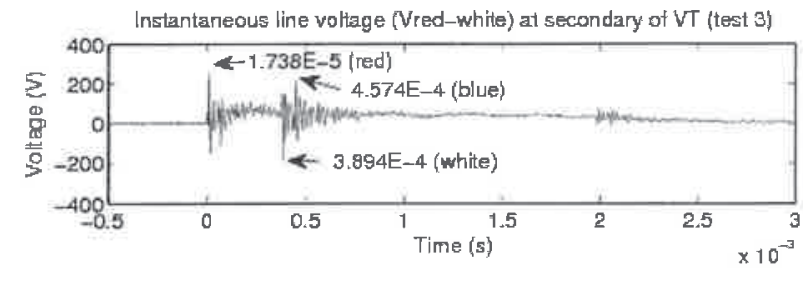

Figure 4: The circuit breaker pole closing times obtained from measurement data.

range of $250 \mathrm{~Hz}$ to $10 \mathrm{kHz}$. The major peaks of signal energy in this range occur at 1.1, 1.8, 2.9 and $5.8 \mathrm{kHz}$.

\subsection{Simulation data}

The data used in section 3.1 was obtained from measurement in the field where the CB poles do not close in an ideal manner. To include this non-ideal characteristic in the simulation model, it is essential to measure and analyse the pole closing times from experimental measurement. Identification of the closing time for each pole during the cable energisation test is established by measuring the line voltage at the secondary winding of the voltage transformer located at the sending end of the cable. From an analysis of the measured red-to-white and white-to-blue voltage waveforms, shown in figure 4 , the details of pole closing sequences and closing times are established and then used during simulation (figure 5). 


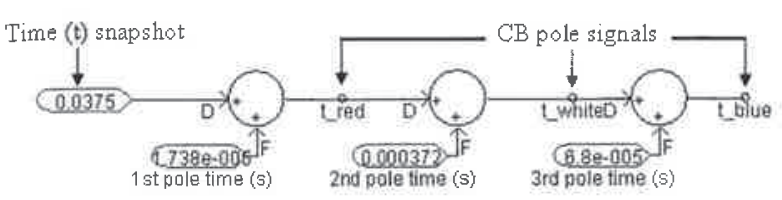

Figure 5: The time settings used for $\mathrm{CB}$ pole closing times in PSCAD/EMTDC.

From figures 4 and 5, it is also clear that the time span between the first and the third pole to close is approximately $0.44 \mathrm{~ms}$. This interval is variable according to the mechanical properties of the $\mathrm{CB}$ and the voltage levels. In high voltage $\mathrm{CBs}$ this span can be as high as $3 \mathrm{~ms}$ (Ryan, 2001).

\subsection{Comparison of simulation data with measured results}

Figures 6 and 7 show the simulated current transient and the frequency spectrum data. From figure 6, the simulated blue-, white- and red-phase current magnitudes are 751, 513 and $1077 \mathrm{~A}$, respectively. Accuracy in applying switching times ensures the blue-phase peak is larger than white-phase peak in the simulation. Comparing these values to the experimental data, especially of the blue- and whitephases, reveals amplitudes of similar order for the corresponding phases. The differences from the measured values are $5.1 \%$ and $2.7 \%$ respectively for the blue- and white-phases.

Slight differences in the simulated and actual POW at wich each CB contact closes is one of the major criteria that governs the outcomes for these transient peaks. However, transient envelope times varied significantly. The model approximated the transient envelope to last $20 \mathrm{~ms}$ for the blue-phase and $15 \mathrm{~ms}$ for white- and red-phases respectively. This indicates the the system damping plays a significant role in dissipating the energy arising from transients in cable energisation. As in the case of measured data, one can postulate that there is still some amount of resistive load near the switching point, which helps the transient to decay faster. On the other hand, for the simulated results, no resistive components (loads) were added to the simulated model. As a consequence, the magnitudes of the oscillation transients were diminishing naturally as a result of system impedances mostly from the cable, overhead lines and other power system components. Incorporating system loads is difficult due to their varyiable characteristics and quite often, detailed parameters are unavailable.

The consistency of this model is further verified by comparing the frequency domain response as illustrated in figure 7 . In this figure, the frequency spectrum seems very poor and only several dominant peaks can be observed for each phase compared to the measured data in figure 3 . The dominant peaks of blue-, white- and red-phases only occur at 1.5, 2.2
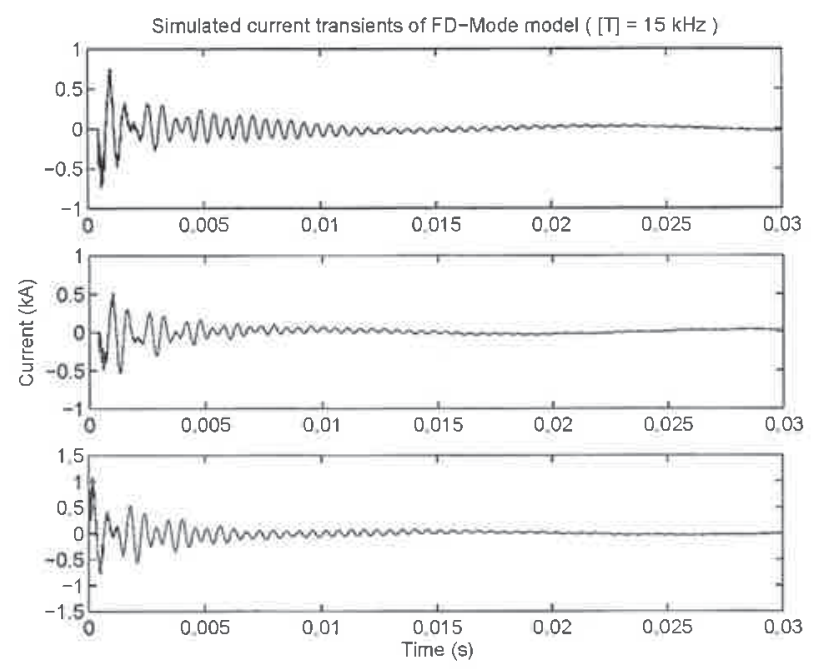

Figure 6: Simulated current energisation transient using FD-Mode model.

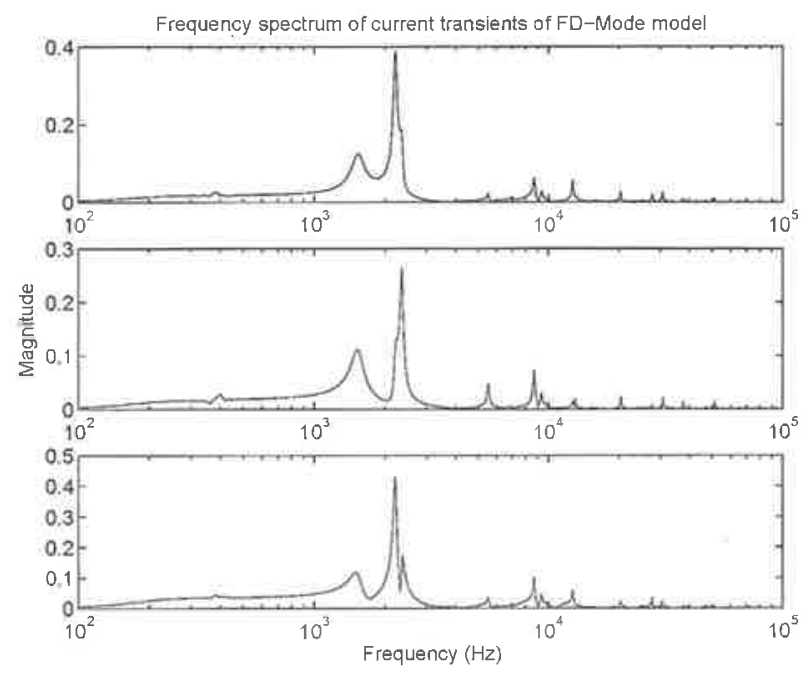

Figure 7: Frequency spectrum of simulated current energisation transient obtained from FD-Mode model.

and $8.7 \mathrm{kHz}$, which is clearly inconsistent with the dominant peaks of the measured data.

The FD-Phase model is more general and suitable for wider range of frequencies. It may be used for modelling underground DC and AC cables and is theoretically suitable to be used for overhead lines of asymmetrical configuration. The advantage of this model over the FD-Mode model is its flexibility since no constant transformation matrix needs to be specified. It is directly formulated in the phase domain and assumes frequency dependence of the internal transformation matrix (Manitoba HVDC Research Center, 2005). Therefore only the CF algorithm parameter needs to be carefully specified for consistent operation of this model.

The waveforms observed in figure 8 exhibit identical shape, amplitude and transient envelope times compared to the simulated results from FD-Mode model. This implies good agreement of the modal transformation setting for the FD-Mode model, which 

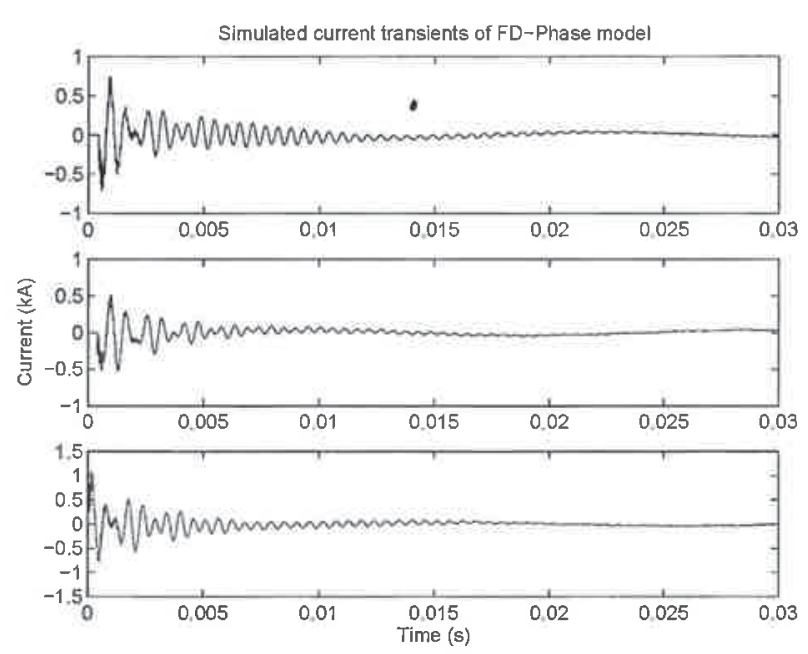

Figure 8: Simulated current energisation transient using FD-Phase model.
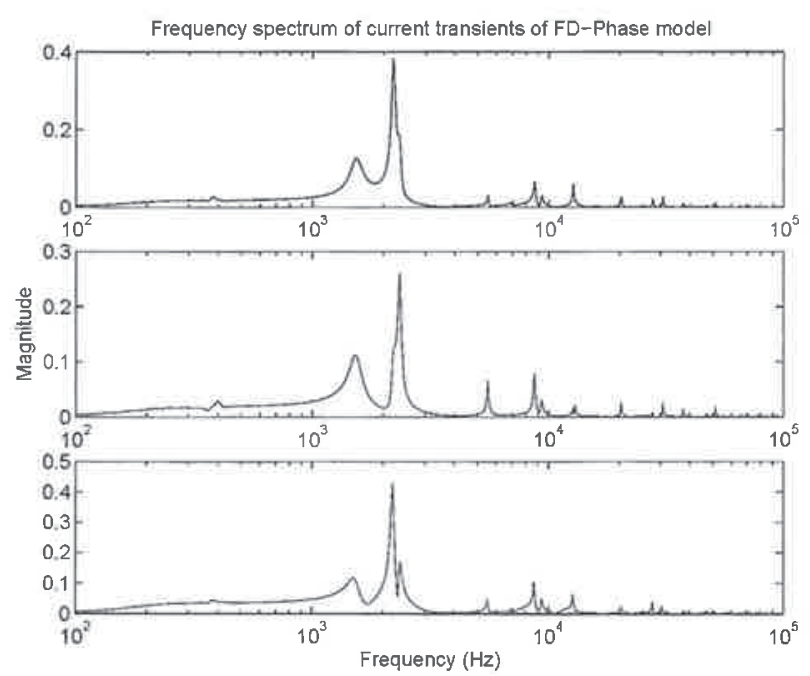

Figure 9: Frequency spectrum of simulated current energisation transient obtained from FD-Phase model.

is at $15 \mathrm{kHz}$. From figure 8, the transient envelope times of the blue- and white-phases are close to 20 and $15 \mathrm{~ms}$, respectively. Consequently the transient peak magnitudes predicted are 736, 514 and $1086 \mathrm{~A}$ for blue-, white- and red-phases, respectively. This reveals the consistency of this model, which is only slightly different to the amplitudes obtained from measured data, specifically of the blue- and whitephases. Only 3.1\% (blue-phase) and 2.5\% (whitephase) deviation to the peaks is observed compared to measurement data. This discrepancy is explained by the dissimilarity of the POW closure of $\mathrm{CB}$ contacts.

Referring to the frequency response of this model based on the frequency domain plots displayed in figure 9, an inconsistency of this model in predicting dominant peaks for simulated current signals is again revealed. The resonant peaks are at 1.5, 2.2 and $8.7 \mathrm{kHz}$, which are similar to the case approximated by FD-Mode model. Again, there would appear to be no commonality regarding dominant peaks relative to the measured data.
The simulated data from both models has been practically compared with measured current energisation transients given in figures 2 and 3. Two parameters considered for time domain data are the over-voltage peaks and the corresponding transient envelope time. It can be seen that from the comparison of both measured and simulated results, their wave-shapes differ considerably. Such discrepancies can be explained using several considerations such as (Daud, 2009):

- the existence of strong coupling effects between cables at high frequencies

- the existence of residual charge in the cable, particularly with the measured data, where the capacitive energy may not have completely diminished after 10 minutes of isolation time

- the mechanical influences of the $\mathrm{CB}$ such as the arc between the CB contacts

- the impact of the FD nature of distribution transformers, which is difficult to model.

However, based on the comparison from available data, it is apparent that the FD-Phase approach is more suitable for the simulation of the energisation transient of the cable. This is purely because of the ability to predict transient magnitudes more accurately. This model is further used to study the statistical behaviour of over-voltages from switching of the cable in section 4 .

\section{STATISTICAL STRESS ANALYSIS}

\subsection{Statistical switching}

Switching surges are random in nature as they are affected by many different factors. Such impacts may be due to the network structure, line parameters as well as the $\mathrm{CB}$ performance. Other than those factors, the $\mathrm{CB}$ pole span, which is the time between the first and the third pole to close, and also the POW of switching angles on the three phases also greatly influences the nature of the transients induced. The latter two cases are considered and described in this section.

Due to the random behaviour of the $\mathrm{CB}$ pole closure, probability analysis is the most practical way in providing useful data on switching over-voltages. A statistical study has been carried out in PSCAD/ EMTDC using two approaches. In the first approach (deterministic), a "systematic switching" (Martinez et al, 2000) concept is used by applying four sets of CB poles closure schemes obtained from measurement data displayed in table 1.

The second approach makes use of probabilistic techniques where the random nature of $C B$ poles are simulated using a random-normal distribution and applied at every aiming point sectionalised over the entire cycle of power frequency voltage. Each aiming point is assumed to generate more than 100 
Table 1: Circuit breaker poles switching settings.

\begin{tabular}{|c|c|c|c|}
\hline Tests & $\begin{array}{c}\text { Phase-A } \\
\text { (ms) }\end{array}$ & $\begin{array}{c}\text { Phase-B } \\
\text { (ms) }\end{array}$ & $\begin{array}{c}\text { Phase-C } \\
\text { (ms) }\end{array}$ \\
\hline Test 1 & 0.0095 & 0.0655 & 0.1295 \\
\hline Test 2 & 0.0168 & 0.5288 & 0.5968 \\
\hline Test 3 & 0.0174 & 0.3894 & 0.4574 \\
\hline Test 4 & 0.0173 & 0.7652 & 0.8332 \\
\hline
\end{tabular}

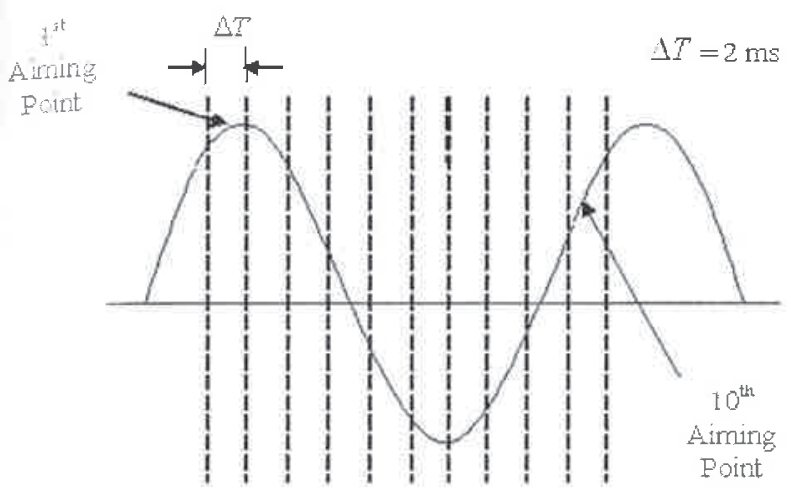

Figure 10: Single-phase view of aiming point settings for $2 \mathrm{~ms}$ pole span.

sets of over-voltage data from random and iterative runs. Different pole span settings are considered and varied from $0.8 \mathrm{~ms}$ to up to $3 \mathrm{~ms}$. An example of aiming point settings for $2 \mathrm{~ms}$ pole span is as illustrated in figure 10.

\subsection{Result from first (deterministic) approach}

Based on the overall results from the application of each scheme in table 1, the significant over-voltage peaks for each phase at the sending and receiving ends are summarised in table 2.

At the sending end, the highest over-voltage peak is $1.84 \mathrm{pu}$ generated from the third case. The traveiling wave phenomena causes the most severe over-voltage peaks at the receiving end when no loads are connected. This is due to superposition of voltage waves. For instance, the over-voltage peak magnitudes, especially in the case of Tests 1 and 2, energisation schemes, all fall close to 2 pu. Overall, in all of the cases, the sending- and receiving-end over-voltage peak values fall in the range of 1.74 to $1.84 \mathrm{pu}$ and 1.84 to $2.06 \mathrm{pu}$, respectively.

\subsection{Results from second (probabilistic) approach}

In the probabilistic approach, the frequencies of maximum value of voltage magnitudes obtained are described using probability density functions for each case of pole span as shown in figure 11.

From figure 11, the sending-end peak magnitudes fall in the average of $1.85,1.79$ and $1.79 \mathrm{pu}$, which occurs at the frequencies of $0.8 \%, 1.6 \%$ and $4 \%$, respectively, for the corresponding 1, 2 and $3 \mathrm{~ms}$ spans. Similarly, at the receiving end, $1.6 \%, 10 \%$ and $16 \%$ of the time, the magnitudes tend to be in the order of 2.05, 1.98 and 1.99 pu for 1,2 and $3 \mathrm{~ms}$ spans, respectively. It is obvious that higher magnitudes are obtained from smaller pole span but the occurrences are very low. Inversely, larger pole spans are more prone to produce a higher frequency of occurrences of relatively lower voltage magnitudes. Overall peak magnitudes are decreasing with increase pole span settings. However there is only a very small percentage difference (over-voltage at sending end) in terms of the 1 and $3 \mathrm{~ms}$ spans.

It is apparent that the results observed in figure 11 are more realistic compared to the deterministic approach as different pole span of $\mathrm{CB}$ can be considered. The consistency of results from simulation can be increased by increasing the number of energisations for each case. However the variation of pole span studied are based on maximum possible span of $C B$ in extra- and ultra-high voltage systems (Ryan, 2001). In this case, it is uncertain for the nominal pole span of the CB under study due to unavailability of data from manufacturer.

\subsection{Results for the pole span below $1 \mathrm{~ms}$ (probabilistic)}

Based on the data displayed in table 1, the maximum span tends to vary between 0.1 and $0.8 \mathrm{~ms}$ for each case, respectively. Therefore, it is also crucial to consider the pole span within the range quoted by measurement data since it represents the real situation.

It has been postulated in this study, that the nominal pole span for the $\mathrm{CB}$ under study will vary within the range of between 0.2 and $0.8 \mathrm{~ms}$. In figure 12 , the sending and receiving end magnitudes are found to vary between the range of 1.81 to $1.88 \mathrm{pu}$ and 2.01

Table 2: Significant overvoltage peaks from deterministic approach.

\begin{tabular}{|c|c|c|c|c|c|c|}
\hline \multirow{2}{*}{ Tests } & \multicolumn{3}{|c|}{ Sending end peaks(pu) } & \multicolumn{3}{c|}{ Receiving end peaks (pu) } \\
\cline { 2 - 7 } & Phase-A & Phase-B & Phase-C & Phase-A & Phase-B & Phase-C \\
\hline Test 1 & 1.80 & 1.76 & 1.77 & 2.04 & 2.06 & 2.01 \\
\hline Test 2 & 1.79 & 1.80 & 1.82 & 2.01 & 1.97 & 2.00 \\
\hline Test 3 & 1.84 & 1.80 & 1.78 & 1.96 & 1.95 & 1.88 \\
\hline Test 4 & 1.77 & 1.75 & 1.74 & 1.86 & 1.84 & 1.88 \\
\hline
\end{tabular}



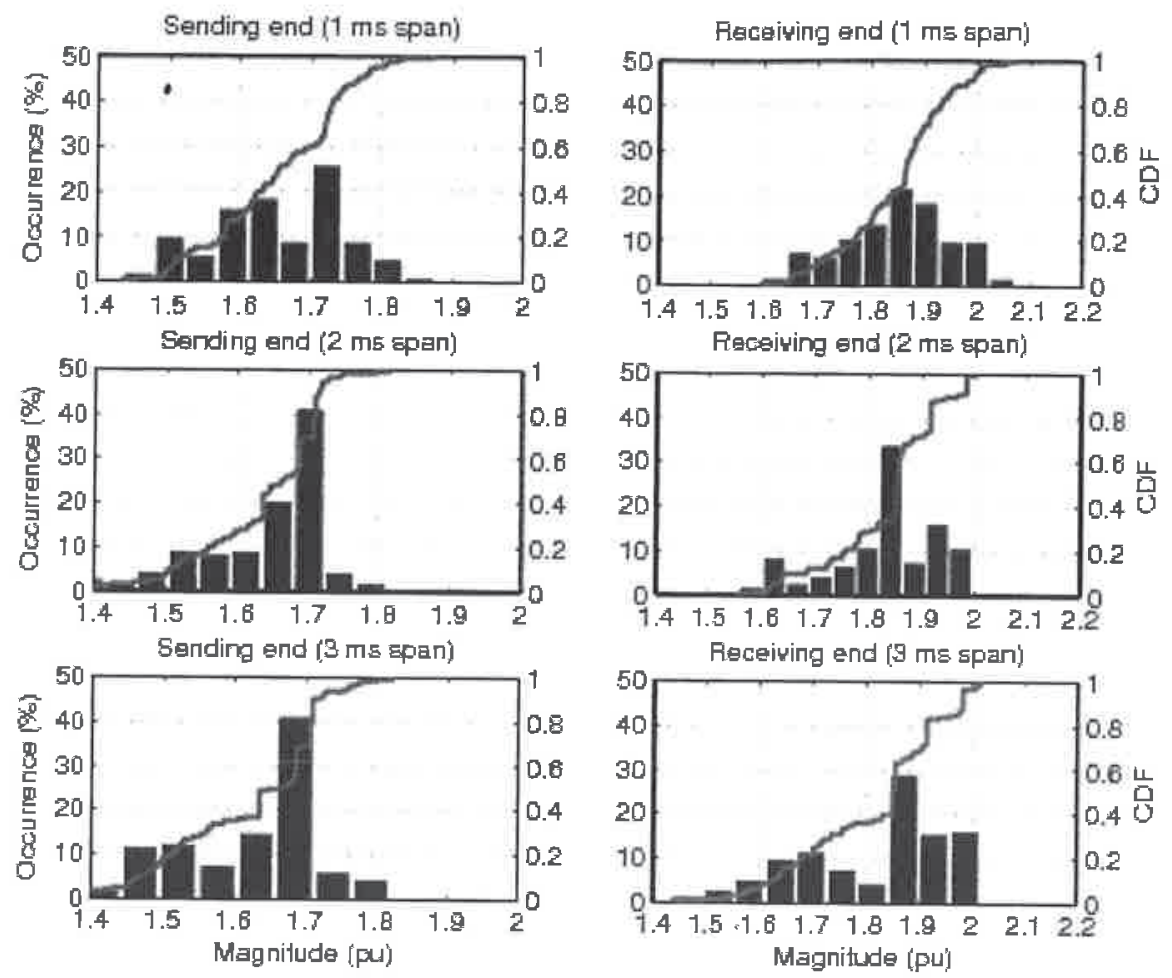

Figure 11: Sending end and receiving end probability density and the corresponding cumulative distribution curves for 1,2 and $3 \mathrm{~ms}$ pole spans studied based on probabilistic approach (case-peak method).
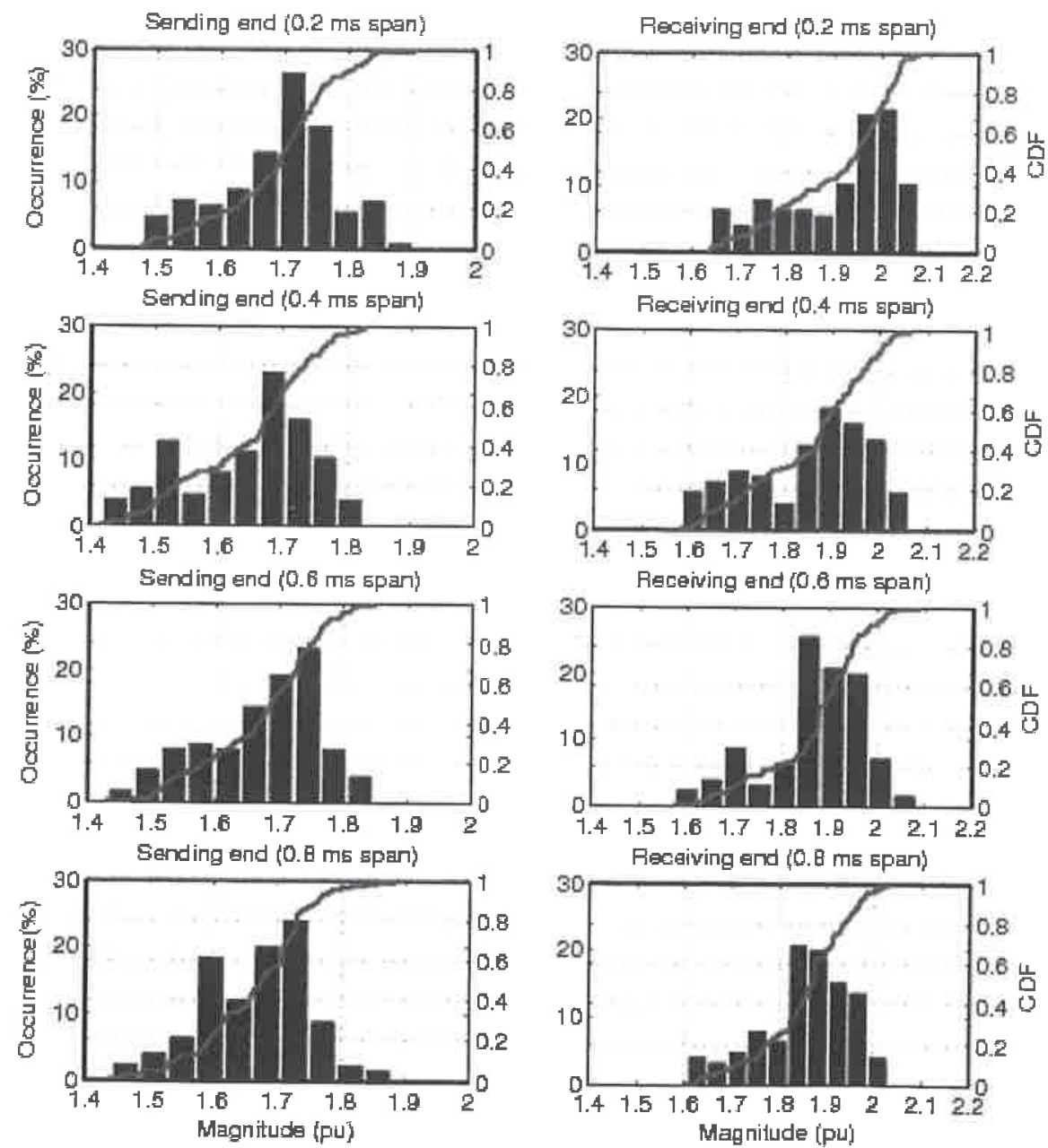

Figure 12: Sending end and receiving end probability density and corresponding cumulative distribution curves for the pole span below $1 \mathrm{~ms}$ (case peak method). 
Table 3: Relevant statistical information for different cases of circuit breaker pole span.

\begin{tabular}{|c|c|c|c|c|c|c|c|c|}
\hline \multirow{2}{*}{ CB span (ms) } & \multicolumn{2}{|c|}{ Mean (pu) } & \multicolumn{2}{c|}{ Max. (pu) } & \multicolumn{2}{c|}{ Std dev. (pu) } & \multicolumn{2}{c|}{ 2\% value (pu) } \\
\cline { 2 - 9 } & SE & RE & SE & RE & SE & RE & SE & RE \\
\hline 0.2 & 1.69 & 1.90 & 1.90 & 2.07 & 0.09 & 0.12 & 1.88 & 2.15 \\
\hline 0.4 & 1.65 & 1.85 & 1.82 & 2.06 & 0.1 & 0.12 & 1.85 & 2.10 \\
\hline 0.6 & 1.67 & 1.86 & 1.85 & 2.08 & 0.09 & 0.10 & 1.86 & 2.08 \\
\hline 0.8 & 1.67 & 1.85 & 1.88 & 2.03 & 0.08 & 0.09 & 1.84 & 2.05 \\
\hline 1 & 1.65 & 1.85 & 1.87 & 2.07 & 0.09 & 0.10 & 1.85 & 2.05 \\
\hline 2 & 1.64 & 1.84 & 1.81 & 2.00 & 0.08 & 0.10 & 1.81 & 2.04 \\
\hline 3 & 1.62 & 1.82 & 1.82 & 2.02 & 0.11 & 0.13 & 1.84 & 2.09 \\
\hline
\end{tabular}

to $2.05 \mathrm{pu}$, respectively. These ranges are distinctly higher than the data quoted in figure 11. Since, the pole span of $0.8 \mathrm{~ms}$ is considered close to the Test 4 energisation schemes of the first (deterministic) approach. Comparing the related results of this case, a very small difference, around $6 \%$, between the two approaches is obtained. However, the data from the second technique (probabilistic) are recommended since they are based on an approach that is closer to reality.

Based on the statistical information displayed in figmes 11 and 12, the relevant data, such as mean magnitudes, maximum magnitudes, standard deviation as well as $2 \%$ probability values, are deduced and summarised in table 3 .

5

\section{CONCLUSION}

The suitability of dedicated PSCAD/EMTDC cable models, namely the FD-Mode and FD-Phase models, to simulate the nature of current and voltage transients when energising a $132 \mathrm{kV}$ underground cable has been explored. Based on the comparison of the data obtained from simulation with the measured resilts, the FD-Phase model was found to give better performance. This reveals the suitability of an FDPhase model especially when it comes to evaluating high frequency effects due to the switching of a high voltage underground cable.

The FD-Phase model was further used to analyse the impact of transients introduced, particularly the statistical distribution of peak magnitude over-voltages, at the sending- and receiving-end of the cable respectively. Such an approach has been motivated by the need for analysis of the impact of (CB) contact closure, which are random in nature. Results from deterministic and probabilistic a proaches revealed that energisation of an unloaded cable at the point of 1 pu of power frequency voltage resuls in approximately $2 \mathrm{pu}$ of over-voltage at the receiving end of the cable. At the sending end, the magnitudes may increase to levels as high as approximately $1.8 \mathrm{pu}$. The data of the receiving end magnitudes obtained from both techniques are still at the average level compared to typical values indicated by the IEC standard (IEC, 1996). These values are not high enough to cause a problem and further studies to limit the transients may not be required. In the work, the data from probabilistic techniques are recommended as their approach is closer to a realistic scenario.

\section{ACKNOWLEDGEMENT}

The data used for this research, such as the underground cable data, surrounding network and energisation test results, were provided by Endeavour Energy (formerly Integral Energy). The assistance of the University of Wollongong Endeavour Energy Power Quality and Reliability Centre is gratefully acknowledged.

\section{REFERENCES}

Daud, M. Z. 2009, "Transient behaviour modelling of underground high voltage cable systems", Master's thesis, School of Electrical, Computer and Telecommunications Engineering (SECTE), NSW, Australia, July.

Gole, A. M., Durbak, D. W., Camm, E. H., Marz, M., Degeneff, R. C., O'Leary, R. P., Natarajan, R., MartinezVelasco, J. A., Leeand, K. C., Morched, A., Shanahan, R., Patico, E. R., Thomann, G. C., Spherling, B., Keri, A. J. F., Woodford, D. A., Rugeles, L., Rashkes, V. \& Sarshar, A. 2009, "Modeling guidelines for switching transients", IEEE PES Switching Transients Task Force, 15 August, www.ee.umanitoba.ca/ gole/ wg15.08.09/switch.pdf.

Gustavsen, B., Irvin, G., Mangelrod, R., Brandt, D. \& Kent, K. 1999, "Transmission line models for the simulation of interaction phenomena between parallel AC and DC overhead lines", International Conference on Power Systems Transients (IPST), Budapest, Hungary, June, pp. 61-67.

IEC, 1996, IEC STD 60071-2 Ed. 3 Insulation coordination-part 2: Application guide, technical report. 
IEC, 2006, IEC STD 60071-1 Ed. 8 Insulation coordination - part 1: Definitions, principles and rules, technical report.

IEEE, 1995, IEEE Std 1159-1995 IEEE recommended practice for monitoring electric power quality, November.

Indulkar, C. S. \& Kothari, D. P. 1996, Power System Transients: A Statistical Approach, Prentice-Hall India Pty. Ltd., New Delhi, India.

Jung, C. K., Lim, K. S., Lee, J. B. \& Kang, J. W. 2009, "Switching transient studies of $345 \mathrm{kv}$ combined transmission systems", Asia and Pacific Transmission Distribution Conference Exposition, October, pp. 1-5.

Kho, D. T. A., Greenwood, M. D. \& Smith, K. S. 2009, "Analysis of switching over-voltages in a threeended $400 \mathrm{kv}$ cable system", Proceedings of the $44^{\text {th }}$ International Universities Power Engineering Conference (UPEC), September, pp. 1-5.

Lee, K. C. \& Poon, K. P. 1990, “Statistical switching overvoltage analysis of the first BC Hydro phase shifting transformer using the Electromagnetic Transients Program", IEEE Transactions on Power Systems, Vol. 5, No. 4, November, pp. 1054-1060.

Manitoba HVDC Research Center, 2005, PSCAD User's Guide v4.2, Manitoba, Canada.

Marti, J. R. 1982, “Accurate modeling of frequencydependent transmission lines in electromagnetic transient simulations", IEEE Transactions on Power Apparatus and Systems, Vol. PAS-101, No. 1, January, pp. 147-157.

Marti, L. 1988, "Simulation of transients in underground cables with frequency-dependent modal transformation matrices", IEEE Transactions on Power Delivery, Vol. 3, No. 3, July, pp. 1099-1110.

Marti, J. R., Marti, L. \& Dommel, H. W. 1993, "Transmission line models for steady-state and transients analysis", IEEE Athens Power Tech, Athens, Greece, September, Vol. 2, pp. 744-750.

Martinez, J. A., Natarajan, R. \& Camm, E. 2000, "Comparison of statistical switching results using gaussian, uniform and systematic switching approaches", IEEE Power Engineering Society Summer Meeting, Vol. 2, pp. 884-889.
Marzinotto, M., Mazzetti, C. \& Schiaffino, P. 2005 , "Statistical approach to the insulation coordination of medium and high voltage cable lines", IEEE Russia Power Tech, June, pp. 1-8.

Morched, A., Gustavsen, B. \& Tartibi, M. 1999, "A universal model for accurate calculation of electromagnetic transients on overhead lines and underground cables", IEEE Transactions on Power Delivery, Vol. 14, No. 3, July, pp. 1032-1038.

Nichols, P., Spoor, D., Gangopadhyay, R. \& Summers, T. 2007, "A practical comparison of a $132 \mathrm{kV}$ cable energisation with ATP modelling techniques", Australasian Universities Power Engineering Conference (AUPEC 2007), Perth, Australia, December, pp. 1-5.

Noda, T., Nagaoka, N. \& Ametani, A. 1996, "Phase domain modeling of frequency-dependent transmission lines by means of an ARMA model", IEEE Transactions on Power Delivery, Vol. 11, No. 1, January, pp. 401-411.

Ryan, H. M. 2001, High Voltage Engineering and Testing, IET.

Semlyen, A. \& Dabuleanu, A. 1975, "Fast and accurate switching transient calculations on transmission lines with ground return using recursive convolutions", IEEE Transactions on Power Apparatus and Systems, Vol. 94, No. 2, March, pp. 561-571.

Semlyen, A. \& Ramirez, A. 2008, "Direct frequency domain computation of transmission line transients due to switching operations", IEEE Transactions on Power Delivery, Vol. 23, No. 4, October, pp. 2255-2261.

Thomas, M. S., Indulkar, C. S. \& Bijwe, P. R. 1989, "Sensitivity analysis of peak swithching overvoltages in underground cables", Electric Machines and Power Systems, Vol. 16, No. 5, pp. 331-342.

Yu, C., Petcharaks, N. \& Panprommin, C. 2000, "The statistical calculation of energization overvoltages, case of EGAT $500 \mathrm{kV}$ lines", IEEE Power Engineering Society Winter Meeting, Vol. 4, pp. 2705-2709.

Zhenchong, C., Xuechang, Y., Pengfei, Y. \& Zhensheng, W. 2006, "Calculation and experiments analysis of switching overvoltage in coaxial underground cable distribution network" ${ }^{\prime \prime}, 12^{\text {th }}$ Biennial IEEE Conference on Electromagnetic Field Computation, June, p. 152. 